\title{
Impact of the actions of an interdisciplinary team in the elderly quality of life \\ ORIGINAL
}

\section{Abstract}

Introduction: Quality of Life (QoL) of the elderly is a complex process, not only by the subjectivity of the term, but also due to the heterogeneity of the elderly. So, analyzing QoL of the elderly is an important way to know better who provides care, allowing the proposal of interventions beyond the treatment of diseases.

Objective: Evaluating the impact of the actions of an interdisciplinary team about the quality of life of seniors.

Method: A longitudinal, analytical, quantitative study conducted with 92 elderly, in which there were applied the SF-36 and the Whoquol-Bref, in July 2012 and April 2013. For data analysis there was used SPSS version 18.0.

Results: The average age was of 68.8 years old. There was a predominance of women with low income and education. After eight months of follow-up, the elderly showed improvement in SF-36 parameters: Functional Capacity; Physical Aspects; Pain; General Health; Vitality and Mental Health; and WHOQOL-Bref (Physical, Psychological and Environment Domain, and Quality of Life).

Conclusion: There was the importance of interdisciplinary actions to improve the quality of life of elderly people, suggesting that interdisciplinarity can be a relevant strategy in the work of health professionals.
Raimunda de Fátima Neves Coêlho ${ }^{1}$, Eliane de Sousa Leite ${ }^{2}$, Francisca Bezerra de Oliveira², Maria do Carmo Andrade Duarte de Farias ${ }^{3}$, Rogéria Mônica Seixas Xavier de Abreu4, Jamili Anbar Torquato 5

1 Academic Unit of Education, Teacher training center, Federal University of Campina Grande. Cajazeiras, Paraíba, Brazil.

2 Academic Unit of Nursing, Teacher training center, Federal University of Campina Grande. Cajazeiras, Paraíba, Brazil.

3 Academic Unit of Life Sciences, Teacher Training Center, Federal University of Campina Grande, Cajazeiras, Paraíba, Brazil.

4 Coordinator of the Shelter Lucas Zorhn. Cajazeiras, Paraíba, Brazil.

5 Master's Program in Health Sciences. University Cruzeiro of Sul, Brazil.

Contact information:

\section{Eliane de Sousa Leite}

巨" elianeleitesousa@yahoo.com.br

Keywords

Elderly; Quality of Life; Health promotion; Interdisciplinary team. 


\section{Introduction}

Aging with Quality of Life (QoL) is an aspiration that enhances life, and depends largely on the social conditions and public policies that guarantee basic rights of citizenship and enable healthy practices such as balanced nutrition, physical activity, pleasurable use of the body, social and occupational inclusion endowed with care and preventive services [1].

Quality of life is a construct that has multiple definitions, because cultural, ethical, religious and personal aspects influence how it is perceived and its consequences. To this day, there is no unanimous definition for the concept. There are several streams of thoughts and a contingent of research, complementary to each other. However, despite the different definitions of the term, there is agreement among authors that in order to assess QoL, using an interdisciplinary approach is needed [2].

To form an interdisciplinary team in health care for the elderly, there are necessary participation, analysis of the problem together and integrating expertise from various fields, with the common goal of promoting and maintaining health. When thinking about promoting the health of the elderly, an interdisciplinary team becomes an essential tool for this goal. In this sense, health professionals should develop their skills and abilities in an integrated way, to operationalize the health actions and result in the improvement of the elderly quality of life.

This philosophy of health work recommends that seek services meet the needs of individuals in their entirety and are capable of responding to cultural differences, if any. However, for this paradigm of health care to succeed, it is necessary that users, professionals, providing institution and community share responsibility and develop partnerships [3].

In this sense, promote healthy aging is therefore a complex task that includes the conquest of good QoL and broad access to services that promote coping with aging issues in the best possible way. These actions are responsible for the increase in health condi- tions by adopting healthy habits, changes in lifestyle, aimed at citizenship and social integration [2].

Therefore, recognizing the QoL of the elderly population is a necessary tool for planning health promotion actions. Based on these, it emphasizes the importance of actions taken by an interdisciplinary team for the third age group, by systematic prevention work, promotion and maintenance of QoL in aging. The objective of the study was to evaluate the impact of the actions of an interdisciplinary team on the quality of life presented by the elderly.

\section{Method}

There was conducted a longitudinal, analytical, quantitative study, developed in the city of Cajazeiras, Paraiba, Brazil, accompanying the Elderly Group "Friends of Sister Fernanda", for eight months, with an interdisciplinary team of professors from the Federal University of Campina Grande (FUCG) and by health professionals from the Municipal Health Department of Cajazeiras and Parish São José Operario, with the following backgrounds: nursing, dentistry, nutrition, medicine, physiotherapy, physical education, educator and psychologist, totaling 15 members. All activities were carried out in groups and always with the presence of two or more professionals. The meetings took place weekly on Wednesdays fairs, sports hall FUCG, which were held physiotherapy and physical exercise; and on Fridays in the auditorium of FUCG where educational activities to promote health and leisure, paint shops, handcrafts and origami were held.

Initially, the elderly group consisted of 120 participants, but only 92 individuals who met the following inclusion criteria were part of the study: being in the group for at least six months; having no functional impairment; presenting ability to understand and verbal communication and participating, during the study period, of all proposed activities. Considering the possibility of the subjects presented 
reduced visual acuity and low level of education, it was decided to apply the instruments in the form of interview.

The variables used to compose the database were: gender, marital status, education, family income, family arrangements, health harmful habits, routine exams and leisure activities. To assessing QoL there were used the Whoqol-Bref instruments (World Health Organization Quality of Life) and the SF-36 (The Medical Outcomes Study 36-item Short Form Health Survey).

The Whoqol-Bref is an abbreviated version of Whoqol-100, which consists of 26 questions, two general about overall QoL and satisfaction with health and the other representing each of the 24 facets that make up the original instrument. It consists of four domains: physical, psychological, social relationships and environment. The higher the score, the better QoL; however, there is no cut-off point for its classification [4].

The SF-36 instrument, a Brazilian version, was translated into Portuguese and adapted for Brazil's culture[5], making it a valid instrument to measure QoL of the population. It contains 36 items, of which 35 are grouped into eight dimensions: functional capacity, pain, physical, emotional and social aspects, mental health, vitality and general health; and a last item that assesses the change of health in time. For each dimension, items are coded, grouped and transformed into a scale ranging from zero (worst health status) to 100 (best health status).

According to the characteristic of the longitudinal study[6], in which every individual is observed more than once, proceeded data collection in two stages: the first, held in July 2012, the socio-demographic questionnaire was applied, the Whoqol-Bref and SF36. After eight months of working with the interdisciplinary team, the second data collection was carried out in April 2013, reapplying the Whoqol-Bref and SF-36 to assess possible changes in the scores of these instruments.
The collected data were entered, forming a database in Excel for Windows XP and later exported to the Statistical Package for Social Sciences (SPSS), version 18.0, to make the analysis. To compare the fields of questionnaires applied between the first and second evaluation, the paired $t$ and Wilcoxon tests were used; while for the analysis of the second question of the SF-36 there was used McNemar-Bowker test. There was adopted significance level of less than $5 \%(p<0.05)$.

The participation of the subjects began by signing the Informed Consent (IC), with the research, the favorable opinion by the Ethics Committee of the State University of Paraiba/UEPB with number Protocol 0289.0 133.000-11, as recommended by Resolution 466/12, of the National Health Council/ National System of Ethics in Research (CNS/SISNEP), which regulates research involving human beings in Brazil7.

\section{Results}

Of the 92 seniors who were part of the survey, $79 \%$ were female, 37\% were widowed and 33\% married, 39\% were illiterate and 39\% had primary education, 50\% received the minimum wage and $39 \%$, two minimum wages. Sixty-six percent of the elderly lived with their family and $30 \%$ lived in sole residence.

Among the health-damaging habits practiced by the respondents, the most frequent were self-medication, with $83 \%$, and $48 \%$ tobacco; $65 \%$ reported performing routine tests annually; $70 \%$ performed some type of leisure activity (gardening, crocheting, painting, etc.).

As the SF-36 were observed positive influence on all scale parameters, when compared to the first assessment for the second, with statistical significance in six of them: Functional Capacity, Physical Appearance, Pain, General Health, Vitality and Mental Health. For Whoqol-bref, there was a statistically 
significant descent in four of the five parameters: Physical, Psychological and Environment Domains and Quality of Life when did the comparison of the first to the second evaluation.

The results obtained using the SF-36 and Whoqol-bref, performed before and after the performance of the interdisciplinary team, enabled verifying significant improvement in the areas evaluated by the two instruments.

In the SF-36, six of the eight domains were statistically different when comparing the two assessments. The Functional Capacity averaged (59.9 \pm 24.7) and (71.8 \pm 16.6) in the first and second evaluation respectively. This area covers the presence and extent of limitation related to physical capacity.
The functional aspect domain showed average (57.9 \pm 36.9) and (70.0 \pm 25.0) in the first and second evaluation respectively. It assesses the limitations on the type of work and how these limitations make it difficult to carry out the work and activities of daily living.

The domain Pain had the lowest score on average $(45.5 \pm 22.6)$ and $(56.1 \pm 17.7)$. According to the results of the first and second assessment, in respect of all domains of the SF-36, you can see an improvement between the first and second evaluation (Table 1).

The General Health obtained average (49.4 \pm 23.0) and (56.7 \pm 14.2$)$ in the first and second evaluation respectively. This area was the most affected

Table 1. Comparison of the results of the domains of the SF-36 questionnaires and Whoqol-Bref between the first and second evaluation. Cajazeiras, Paraiba, 2013.

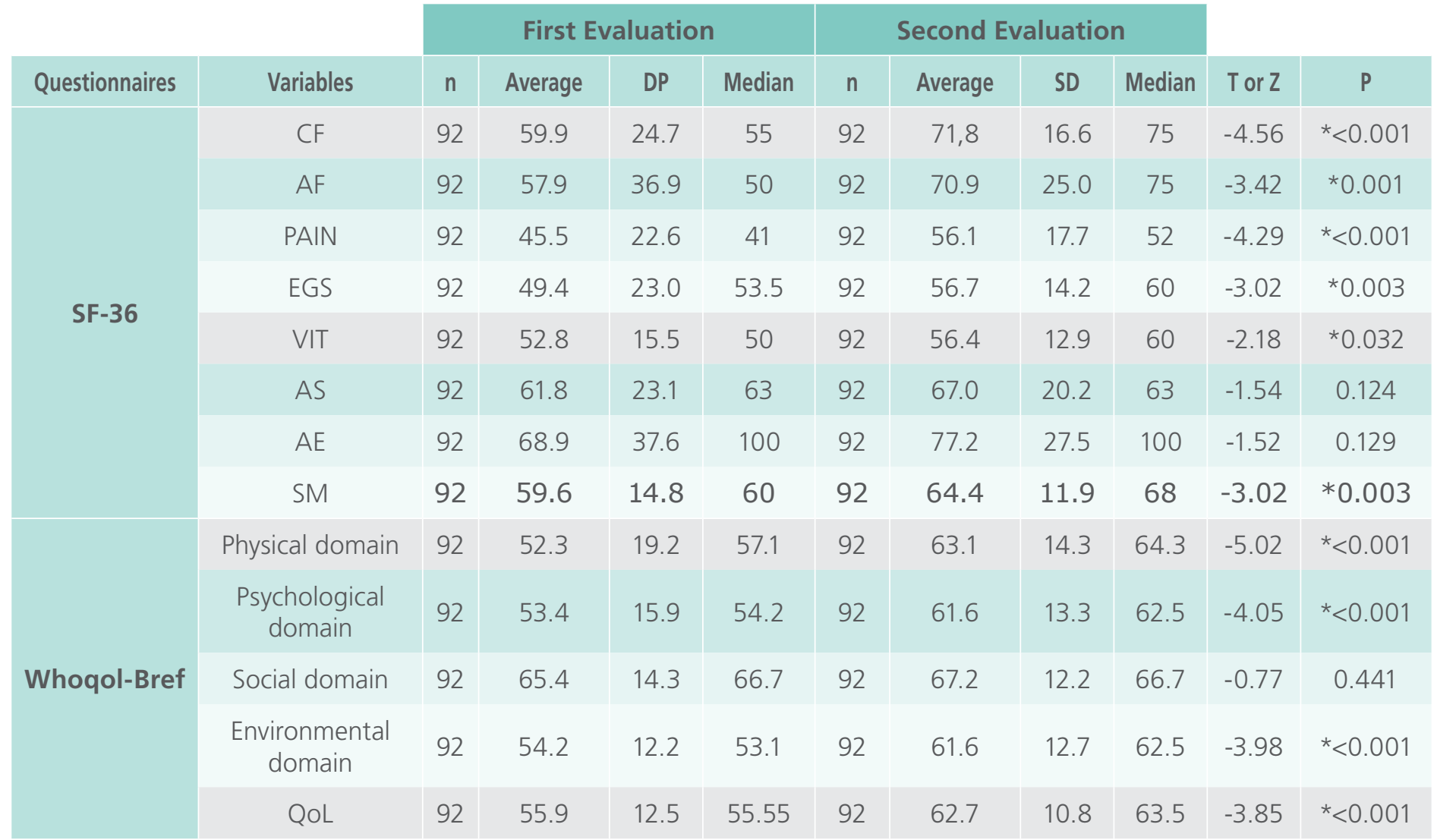

Paired t-test and Wilcoxon test ${ }^{*} p<0$ 0.05. SF-36: CF: Functional Capacity; AF: Physical Aspect; PAIN; EGS: General Health; VIT: Vitality; AS: Social Aspects; AE: Emotional Aspects. Whoqol-Bref: Physical Domain; Psychological Domain; Social Domain; Environment Domain; Quality of Life. 
in the second sample as the SF-36 instrument. It is assessed how the patient feels about his health, globally.

Vitality presented averages (52.8 \pm 15.5) and $(56.4 \pm 12.9)$. This parameter considers the level of energy, vigor and fatigue, as exhaustion and fatigue. The average for Mental Health, in both evaluations, respectively, was (59.6 \pm 14.8$)$ and $(64.4 \pm 11.9)$. This domain refers to questions related to anxiety, depression, changes in behavior or emotional imbalance and psychological well-being.

Regarding the domains of Whoqol-Bref instrument, the Physical Domain showed lower average $(52.3 \pm 19.2)$ and $(63.1 \pm 14.3)$. In it the goal is to assess pain, discomfort, energy and fatigue, sleep and rest, mobility, and instrumental daily life activities, dependence on medication or treatment.

The Psychological Domain had an average lower than expected $(53.4 \pm 15.9)$ and $(61.6 \pm 13.3)$, which refers to positive feelings, thinking, learning, memory and concentration, self-esteem, body image and appearance, negative feelings, religion.

The Environment Domain with average (54.2 \pm 12.2) and (61.6 \pm 12.7$)$ evaluates physical security and protection; home environment; financial resources of health and social care; opportunity to acquire new information and skills; participation and opportunities for recreation/leisure; risk environment; shipping. The domain Global Quality of
Life assesses satisfaction with overall health, averaged (55.9 \pm 12.5$)$ and $(62.7 \pm 10.8)$.

Table 2 refers to Question 2 of the SF-36 instrument. It was analyzed separately in order to see what changes occurred in the health of the participants, when done the following question: "Compared one year ago, how would you rate your health in general now?" Before the data analyzed, we observed a significant difference in the results (Table $\mathbf{2}$ ).

Question 2 of the SF-36 showed a significant improvement in comparison of results between the first and second evaluation. In the first evaluation, in response to question above cited 15 individuals reported being "a little worse now than a year ago", in the second evaluation only seven people have made that statement. Those who said they were with the health "almost the same thing a year ago" in the first evaluation were 41, lowering the number to 19 in the second evaluation.

\section{Discussions}

Quality of life of older people is a complex process, not only by the subjectivity of the term, but also due to the heterogeneity of the elderly. So analyze the QOL of the elderly is an important way to recognize better who provides care, allowing the

Table 2. Comparison of the results of question 2 of the SF-36 between the first and second evaluation. Cajazeiras, Paraiba, 2013.

\begin{tabular}{|c|c|c|c|c|c|c|}
\hline & Results & $\begin{array}{c}\text { Much } \\
\text { better }\end{array}$ & A few better & $\begin{array}{c}\text { Nearly the } \\
\text { same }\end{array}$ & A little worse & Total \\
\hline & Much better & 2 & 1 & 0 & 0 & 3 \\
\hline $\begin{array}{c}\text { Question 2 } \\
\text { Evaluation 1 }\end{array}$ & A few better & 1 & 24 & 6 & 2 & 33 \\
& Nearly the same & 5 & 22 & 10 & 4 & 41 \\
\hline & A little worse & 0 & 11 & 3 & 1 & 15 \\
\hline
\end{tabular}

Test of McNemar-Bowker $-p=0.001$ 
proposal of interventions beyond the treatment of disease.

In this study, the Functional Capacity and Functional Aspect domains had increased scores after the intervention of the interdisciplinary team, assuming that the increase in these parameters resulted from physical and physiotherapy activities held weekly, as well as medical and nursing consultations and medical treatment performed the elderly, in the range of evaluations.

Among the activities that improve functional capacity and physical appearance are the physical activities. Physical exercise improves functional capacity and physical fitness. The benefits deriving from the increased level of physical activity extend from the improvement of functional capacity, blood pressure regulation, reducing the risk of cardiovascular disease, osteoporosis, diabetes and certain cancers[8].

Functional Capacity and the Physical Appearance domains are showing variation according to age, revealing an important investment target in evaluating and promoting the health of older people. Results of the study that followed a cohort of elderly for more than 10 years in São Paulo reinforce the importance of functional capacity, which, along with the cognitive state, was one of the risk factors for mortality[9].

The area Pain evaluates the presence of pain, its intensity and its interference in the physical activities. To minimize the pain symptoms referred by the elderly, who according to the evaluation of health professionals was due, for the most part, of rheumatic diseases, physical therapists, along with the physical educator, performed physical therapy activities, exercise and guidelines for a more specific treatment according to the needs of each elderly person.

Pain in the elderly is now a problem for public health because this symptom decreases the functionality, limiting the elderly in his instrumental and basic activities of daily living. Studies [10] show that the pain is associated with fatigue, sleep disorders, treatment of dependency or drug use; in addition to decreasing the capacity for work, to carry out the activities of daily life, sexual activity, among others.

The values of the domain General Health, found in this study might not have had a better outcome because of physical ailments and emotional, social problems that older people experience in their daily lives. Another study11 using the SF-36 performed to analyze the domain "general health", met the lowest rate (average $=53.58$ ), probably caused by clinical manifestations related to the etiology of hypertension, diabetes, and to treatment.

The Vitality domain, in the population studied may not have presented greater improvement due to the aging process itself, accompanied by rheumatic diseases and chronic diseases, which often leaves the elderly exhausted and tired.

Observing the average values in the area of Mental Health, of the present study, it is assumed that these figures show a commitment on the mental health of the elderly. Research conducted in the State of Minas Gerais, with patients with chronic kidney disease also resembles to this study, when this same field did not improve after the interdisciplinary intervention. This may be related to the evolution of kidney disease and lead to higher possibility of depression, especially the proximity to the start of renal replacement therapy[11].

Two domains of the SF-36 instrument that does not show significant differences were: Social Aspects assesses the integration of the individual in social activities (family, neighbors or group), and Emotional Aspects, which assesses the impact of psychological aspects on the well-being of the elderly.

The physical domain has a wide scope in relation to various aspects of life of the elderly, especially if he is a carrier of an illness and not keeps a proper care of his health. Another study12that conforms to this research, therefore, the Physical Domain had the lowest average, it is the research conducted in the State of Minas Gerais, with chronic kidney dis- 
ease, which undergoes changes in daily life, due to carry out treatment, since he lives depending on the health staff, machinery, medicines and informal support, to maintain the necessary care of his health.

The results of this research to the psychological domain, contradict the assertion that the subjective well-being characterized by positive emotions, well-being, satisfaction, happiness - does not decline with age, and the psychological sphere less affected according to age[13]

The Domain Environment is very important in the perception of the elderly QoL. Positive results in this area confirm adequate QoL[13].

Given what is observed in the middle of the second evaluation in the field Global Quality of Life, QoL sample of respondents elderly improved, overall, after eight months of interdisciplinary intervention. Studies[14-15] found worse QoL of elderly people who were not exposed to any intervention. However, there was improvement in QoL in the elderly who underwent interdisciplinary care interventions. It is revealed through the study data that there is a greater improvement of quality of life variables and also physical for elderly groups that make intervention programs with monitoring, for those who make at home by following guidelines.

Question 2 of the SF-36 showed a significant improvement between assessments. It was observed that the proportion of subjects who reported to have improved in the second evaluation was very considerable. These results confirmed that the interdisciplinary interventions applied to the group of elderly, over the eight months served to improve QoL in all domains assessed by the SF-36 instrument.

\section{Conclusion}

Monitoring by different health professionals can provide the elderly greater access to social, physical, psychological benefits, health and leisure, assisting them to understand and accept the aging process. On the relevance of interdisciplinary attention to the elderly is indeed the need for investment in new professionals to work with the people of the third age, a time with interdisciplinary care can obtain greater survival of elderly person with QoL.

Regarding the instruments used in this research, they presented relevant properties for evaluation in the fields of interest of QoL. However, it is not possible to indicate the "better" or "worse" instrument for this purpose. The results signaled a better performance of the Whoqol-Bref in the population studied, particularly with regard to the time of application of the instrument and the power of discrimination in relation to the impact on QoL.

The results obtained in this study pointed to the need for systemized work with interdisciplinary team to improve health in old age. The search for cultural change, towards the effective implementation of a policy of promotion of health, prevention of diseases and care for the elderly, provides a healthy aging for the population studied.

\section{References}

1. Vitorino LM, Paskulin LM, Vianna LAC. Qualidade de vida de idosos da comunidade e de instituições de longa permanência: estudo comparativo. Rev. Latino-Am. Enfermagem [online]. 2013 Jan/Feb; 21 (spe): 3-11. doi: http://dx.doi.org/10.1590/ S0104-11692013000700002

2. Almeida AJPS, Rodrigues VMCP. The quality of life of aged people living in homes for the aged. Rev. Latino-Am. Enfermagem [online]. 2008; 16(6): 1025-31. doi: http://dx.doi. org/10.1590/S0104-11692008000600014

3. Alexandre TS, Cordeiro RC, Ramos LR. Factors associated to quality of life in active elderly. Rev Saúde Pública. [online]. 2009; 43(4): 13-21. doi: http://dx.doi. org/10.1590/S003489102009005000030

4. Fleck MPA, Louzada S, Xavier M, Chachamovich E, Vieira G, Santos L, Pinzon L. Aplicação da versão em português do instrumento abreviado de avaliação de qualidade de vida “Whoqol - Bref. Rev. Saúde Pública [online]. 2000; 34(2): 17883. doi: http://dx.doi.org/10.1590/S0034-89102000000200012

5. Ciconelli R M. Tradução para o português e validação do questionário genérico de avaliação de qualidade de vida 
"Medical Outcomes Study 36-Item Short-Form Health Survey (SF-36)". São Paulo, 1997. Tese. (Doutorado)-Escola Paulista de Medicina, Universidade Federal de São Paulo, São Paulo, 1997.

6. Pereira MG. Epidemiologia: teoria e prática. Rio de Janeiro: Guanabara Koogan; 2010.

7. Brasil. Ministério da Saúde. Conselho Nacional de Saúde. Comissão Nacional de Ética e Pesquisa - CONEP. Resolução n466/12 sobre pesquisa envolvendo seres humanos. Brasília, DF: MS, 2012.

8. Ramos LR. Epidemiologia do envelhecimento. In: Freitas EV. (Org.). Tratado de geriatria e gerontologia. Rio de Janeiro: Guanabara Koogan; 2010.

9. Binder EF, Schechtman KB, Ehsani AA, Steger-May K, Brown $M$, Sinacore DR. et al. Effects of exercise training on frailty in community-dwelling older adults: results of a randomized, controlled trial. JAGS. 2008;50(12):1921-28. PMID:12473001

10. Cunha LL, Mayrink WC. Influência da dor crônica na qualidade de vida em idosos. Rev. Dor. [online] 2011; 12(2): 120-24. doi: http://dx.doi.org/10.1590/S1806-00132011000200008

11. Brito DMS, Araújo TL, Galvão MTG, Moreira TMM, Lopes MVO. Qualidade de vida e percepção da doença entre portadores de hipertensão arterial. Cad. Saúde Pública. [online] 2008; 24(4):933-940. doi: http://dx.doi.org/10.1590/S0102$311 \times 2008000400025$

12. Santos FR, Filgueiras MST, Chaoubah A, Bastos MG, Paula RB. Efeitos da abordagem interdisciplinar na qualidade de vida e em parâmetros laboratoriais de pacientes com doença renal crônica. Rev. psiquiatr. clín. [online]. 2008; 35(3): 87-95. doi: http://dx.doi.org/10.1590/S0101-60832008000300001.

13. Grasselli CSM, Chaves ECL, Simão TP, Botelho PB, Silva RR. Avaliação da qualidade de vida dos pacientes submetidos à hemodiálise. Rev Bras Clin Med. 2012; 10(6): 503-7.

14. Neri AL. Qualidade de vida velhice: enfoque interdisciplinar. Campinas, SP: Editora Alínea; 2011.

15. Rosa TEC, Benício MHDA, Latorre MRDO, Ramos LR. Fatores determinantes da capacidade funcional entre idosos. Rev Saúde Pública. 2008; 37(1): 40-48. doi: http://dx.doi.org/10.1590/ S0034-89102003000100008.

\section{Comment on this article:}

\section{(f) 8 in $8+\mathbf{S}$ P}

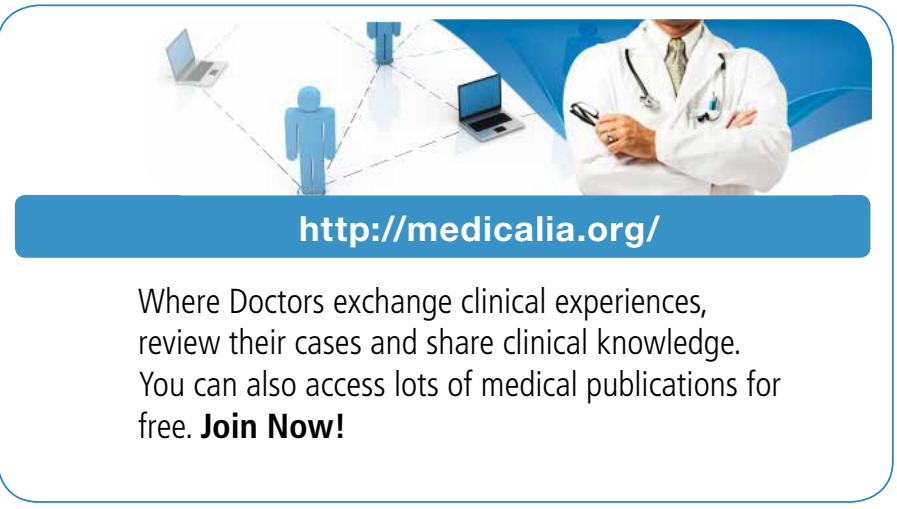

\section{Publish with iMedPub}

\section{http://www.imed.pub}

International Archives of Medicine is an open access journal publishing articles encompassing all aspects of medical science and clinical practice. IAM is considered a megajournal with independent sections on all areas of medicine. IAM is a really international journal with authors and board members from all around the world. The journal is widely indexed and classified Q1 in category Medicine. 